\title{
Evidence-based management as a basis for evidence- based medical consultation
}

\section{Edris Hasanpoor, ${ }^{1}$ Mohammadkarim Bahadori, ${ }^{2}$ Maryam Yaghoubi, ${ }^{2}$ Elaheh Haghgoshayie, ${ }^{1}$ Alireza Mahboub-Ahari ${ }^{3}$}

\subsection{6/bmjebm-2018-111104}

${ }^{1}$ Department of Healthcare Management, Maragheh University of Medical Sciences, Maragheh, Iran ${ }^{2}$ Health Management Research Center, Baqiyatallah University of Medical Sciences, Tehran, Iran ${ }^{3}$ Department of Health Economics, Iranian Center of Excellence in Health Management, School of Management and Medical Informatics, Tabriz University of Medical Sciences, Tabriz, Iran

Correspondence to: Dr Elaheh Haghgoshayie, Department of Healthcare Management, School of Nursing and Midwifery, Maragheh University of Medical Sciences, Maragheh, Iran; ezd_ehm2010@yahoo. com

\section{Introduction}

Healthcare quality is a basic demand of patients in a health services delivery system, and it is one of the rights of every patient. ${ }^{1}$ Therefore, a high-quality consultation is part of the rights of a patient as a citizen. ${ }^{12}$ On the other hand, most physicians, healthcare managers and policymakers will express that the patient-physician relationship is central to healthcare; unfortunately, despite this advocacy, patients seem to be easily overlooked. ${ }^{3}{ }^{4}$ Medical consultation is essential to all aspects of healthcare, from history taking to providing information to patients, as it provides the primary means for the diagnosis of a disease, treatment of illness and prevention of health problems. ${ }^{1256}$ Medical consultation is a dynamic, interactive process, during which the physician and the patient co-construct and negotiate the meanings and means of talk. ${ }^{48}$ Its success is seen as the joint responsibility of the doctor and the patient. Understanding patients' concerns, preferences and requests is vital in order for physicians to improve the quality of the consultation. ${ }^{8}$ However, previous studies have indicated that there is dissatisfaction about the quality of consultation in every phase of a medical encounter. ${ }^{1}{ }^{9-11}$ Using evidence-based medical consultation (EBMC) could, therefore, help to enhance the consultation. ${ }^{1912}$

Evidence-based management (EBMgt) requires high-quality decisions based on the best available evidence. EBMgt has been defined as 'making decisions through the conscientious, explicit, and judicious use of six scientific and research evidence, facts and information of hospital, political-social development plans, managers' professional expertise, ethical-moral evidence and values and expectations of all stakeholders in the decision-making process with fundamental six phases. ${ }^{13-16}$ These six phases (6A) included asking, acquiring, appraising, aggregating, applying and assessing. ${ }^{14} 1517$ Therefore, we used the EBMgt model to design the EBMC framework to improve the quality of a patient-physician relationship.

\section{Proposed model for EBMC}

EBMC is a dynamic, interactive process between the physician and the patient based on the best evidence in order to improve the patient's health outcomes in clinical decision-making. ${ }^{1}{ }^{12} \quad 18$ According to the principles and foundations of EBMgt, EBMC consisted of six sources of evidence in a six-step process (figure 1). These are scientific and research evidence, facts and information of the disease, socioeconomic status, physicians' professional expertise, ethical-moral evidence, and values and expectations of all patients. Indeed, these sources are the main considerations of any consultation. ${ }^{14-16} 19$

Scientific and research evidence is related to the diagnosis skills of physicians, and physicians must use the best scientific evidence. Facts and information about the patient can be good evidence for correct diagnosis. The patient's history and detailed examination in medical consultations are among the best evidence for clinical decisions. Moreover, the socioeconomic conditions of the patient may affect the treatment process.

\section{Check for updates}

๑ Author(s) (or their employer(s)) 2020. No commercial re-use. See rights and permissions. Published by BMJ.

To cite: Hasanpoor E, Bahadori M, Yaghoubi M, et al. BMJ Evidence-Based Medicine 2020;25:83-84.

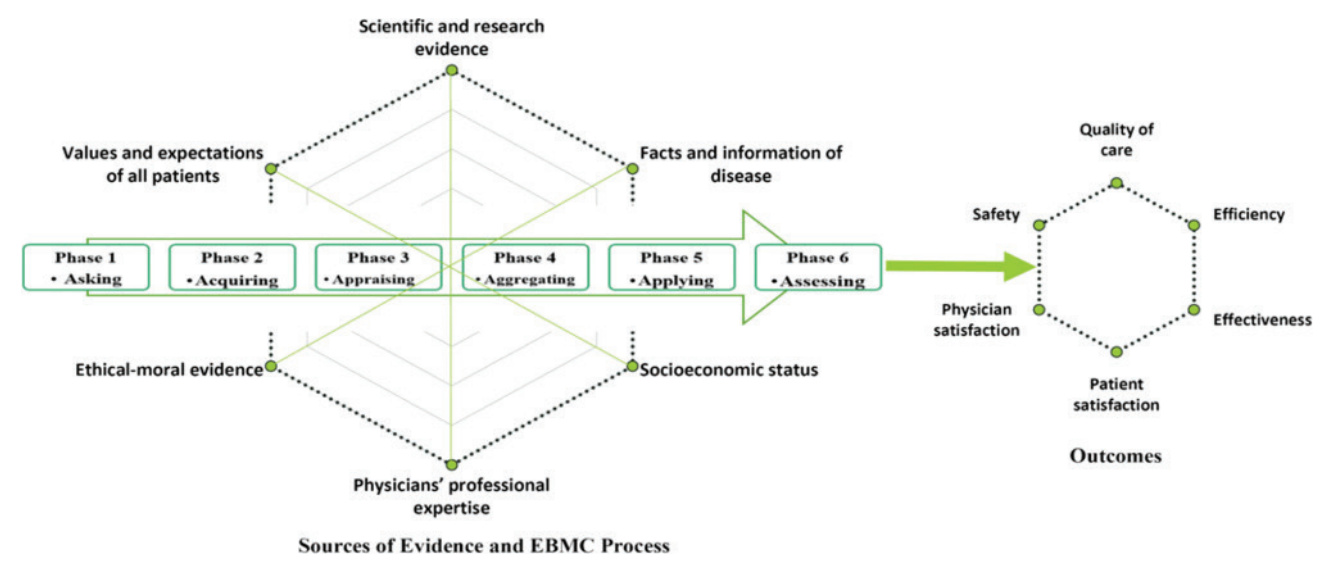

Figure 1 Proposed model of evidence-based medical consultation (EBMC). 
For example, a package of social prescribing can be effective in helping patients to manage their disease. Another source of evidence for an effective visit is physicians' professional expertise and skills that create synergy among sources of evidence. For example, communication skills can strengthen the use of ethicalmoral evidence. Finally, respect for the patient's rights and good behaviour are among the aspects of evidence-based doctors. This evidence is related to values and preferences of all patients. Physicians provide structure for medical consultation based on quality using six sources of evidence.

As shown in figure 1, we identified the sources, processes and outcomes of EBMC. The process of medical consultations based on evidence includes six steps: asking (translating a practical issue or the patient's problem into an answerable question), acquiring (systematically searching to retrieve the evidence among the six main sources), appraising (critically judging the trustworthiness and relevance of the evidence), aggregating (weighing and pulling together the evidence), applying (using the evidence into the decision-making process) and assessing (evaluating the outcome of the decision taken). A full evidencebased doctor is a person who applies all six sources of evidence in the diagnosis and examination process using the basic six phases.

\section{Conclusion}

EBMC can improve decisions and quality of visits, treatment effectiveness, efficiency of service, quality of care, patient safety, and physician and patient satisfaction. These six outcomes have been retrieved from evidence-based decision-making in medical consultations. There is a primary need for improving the education of all physicians in the use of sources of evidence and the EBMC process. Communication skills during interaction with patients must continuously improve throughout the physicians' professional career. It is suggested that physicians provide the necessary infrastructures for sources of evidence and eliminate barriers to EBMC. Development of evidence-based clinical decision-making committee can be useful. Physician and audit teams should consider including these topics in their list of requirements for training programmes. Practice and interventions are needed to bring model, the content and the context, to provide better healthcare services. An integrated evidence-based approach can improve the quality of the patient-physician relationship in healthcare delivery.

Contributors All the authors contributed to the first draft of the paper, revised it for critical, reasonable content, and reviewed the final draft.

Competing interests None declared.

Patient consent Not required.

Provenance and peer review Not commissioned; internally peer reviewed.

\section{References}

1. Janati A, Hasanpoor E, Aslan F, et al. Evaluating visit quality in plan of health sector evolution in Iran: A local survey from Tabriz. International Journal of Epidemiologic Research 2017;4:69-77.

2. Howie JG, Heaney DJ, Maxwell M, et al. Developing a 'consultation quality index' (CQI) for use in general practice. Fam Pract 2000;17:455-61.

3. Bensing JM, Deveugele M, Moretti F, et al. How to make the medical consultation more successful from a patient's perspective? Tips for doctors and patients from lay people in the United Kingdom, Italy, Belgium and the Netherlands. Patient Educ Couns 2011;84:287-93.

4. Mazzi MA, Rimondini M, van der Zee E, et al. Which patient and doctor behaviours make a medical consultation more effective from a patient point of view. Results from a European multicentre study in 31 countries. Patient Educ Couns 2018;101:1795-803.

5. Mohebbifar R, Mohseni M, Mohseni M, et al. Outpatient waiting time in health services and teaching hospitals: a case study in Iran. Glob J Health Sci 2013;6:172-80.

6. Kuusela M, Vainiomäki P, Hinkka S, et al. The quality of GP consultation in two different salary systems A Finnish experience. Scand J Prim Health Care 2004;22:168-73.

7. Finset A, Mjaaland TA. The medical consultation viewed as a value chain: a neurobehavioral approach to emotion regulation in doctor-patient interaction. Patient Educ Couns 2009;74:323-30.

8. Li S, Gerwing J, Krystallidou D, et al. Interaction-A missing piece of the jigsaw in interpreter-mediated medical consultation models. Patient Educ Couns 2017;100:1769-71.

9. Kiguli S, Mafigiri D, Nakigudde J, et al. A qualitative study of caregivers' expectations and communication desires during medical consultation for sick children in Uganda. Patient Educ Couns 2011;84:217-22.

10. Laidlaw TS, Kaufman DM, Macleod H, et al. Patients' satisfaction with their family physicians' communication skills: a Nova Scotia survey. Acad Med 2001;76:S77-S79.

11. Kravitz RL. Measuring patients' expectations and requests. Ann Intern Med 2001;134:881-8.

12. Hasanpoor E, JafarAbadi MA, Saadati M, et al. Provincial level survey provides evidence for remarkably short outpatient visit length in Iran. International Journal of Hospital Research 2015;4:77-82.

13. Hasanpoor E, et al. Barriers, facilitators, process and sources of evidence for evidence-based management among health care managers: a qualitative systematic review. Ethiop J Health Sci 2018;28:665-80.

14. Janati A, Hasanpoor E, Hajebrahimi S, et al. Health care managers' perspectives on the sources of evidence in evidence-based hospital management: a qualitative study in Iran. Ethiop J Health Sci 2017;27:659-68.

15. Janati A, Hasanpoor E, Hajebrahimi S, et al. Evidence-based management healthcare manager viewpoints. Int J Health Care Qual Assur 2018;31:436-48.

16. Janati A, Hasanpoor E, Hajebrahimi S, et al. An evidence-based framework for evidence-based management in healthcare organizations: a delphi study. Ethiop J Health Sci 2018;28:305-14.

17. Hasanpoor E, Janati A, Arab-Zozani M, et al. Using the evidence-based medicine and evidence-based management to minimise overuse and maximise quality in healthcare: a hybrid perspective. BMJ Evid Based Med 2020;25:3-5.

18. Mazzi MA, Rimondini M, van der Zee E, et al. Which patient and doctor behaviours make a medical consultation more effective from a patient point of view. Results from a European multicentre study in 31 countries. Patient Educ Couns 2018;101:165-6.

19. Kiaei MZ. Hospital managers' perception of recent health care reform in teaching hospitals of Qazvin, Iran. Biotechnology and Health Sciences 2015;2. 